\title{
Tetralogy of Fallot, Cardiac Hypertrophy, Pulmonary Hypertension, and Anomalies of Great Vessels in Fetuses and Neonates of WKY/NCrj Rats
}

\author{
TOSHIRO KURIBAYASHI, KAZUTOSHI SHIMOO, TAKASHI NAKAMURA, KENZI HAMAOKA, \\ MASAO NAKAGAWA, YASUHIKO IBATA, TADASHI MIZUTA, TOMOHIKO KOMEDA, AND \\ AKINOBU NAGAOKA \\ Department of Anatomy [T.Ku, Y.I.], Department of Medicine [K.S., T.N., M.N.], Children's Research Hospital \\ [K.H.], Kyoto Prefectural University of Medicine, Kyoto, Meiji Institute of Health Science, Odawara [T.M.], \\ and Central Research Division, Takeda Chemical Industries, Ltd., Osaka [T.Ko., A.N.], Japan
}

\begin{abstract}
We examined anatomically the hearts, lungs, and great vessels of $269 \mathrm{WKY} / \mathrm{NCrj}$ rats at three fetal and three neonatal stages. Severe pulmonary valve thickening was present in 16 and ventricular septal defects with overriding of the aorta in 15 of the 90 near-term fetuses and in 10 and nine, respectively, of the 79 neonates at $2-4 \mathrm{~d}$ of age. These abnormalities occurred together (tetralogy of Fallot) in seven of the near-term fetuses and in five of the neonates. A narrow pulmonary outflow tract was present in $55 \%$ of the fetuses and in $56 \%$ of the neonates. The wall of the pulmonary arterial branch was abnormally thick in $19 \%$ of the fetuses and in $26 \%$ of the neonates, most of which did not have septal defects. In about $80 \%$ of the fetuses, the middle latitudinal muscle bundle of the ventricular septum was not continuous with the left ventricular free wall, but rather with the right; after birth, it was discontinuous with both free walls. The heart was abnormally heavy in $49 \%$ of the 79 neonates. In about half of the heavy hearts, there were no septal defects or pulmonary valvular and arterial lesions. There were double aortic arches in four and right aortic arches in six of the total WKY fetuses and neonates; the ductus arteriosus was abnormally small in $\mathbf{4 7 \%}$ and the aorta was large in $51 \%$ of the near-term fetuses. This constellation of congenital heart disease is genetic in origin, but altered by hemodynamics late in fetal life. (Pediatr Res 28: 429-436, 1990)
\end{abstract}

\section{Abbreviations}

RVFW, right ventricular free wall

IVS, ventricular septum

LVFW, left ventricular free wall

MLB, middle latitudinal muscle bundle

$G$, days of gestation

A, days after birth

TOF, tetralogy of Fallot

P-valve, pulmonary valve

VSD, ventricular septal defect

POT, pulmonary outflow tract

PA, pulmonary artery

WT/LR, wall thickness/lumen radius ratio

Received April 24, 1989: accepted June 13, 1990

Correspondence and reprint requests: Toshiro Kuribayashi, M.D., Second Department of Anatomy, Kyoto Prefectural University of Medicine, KawaramachiHirokoji, Kamikyo-ku, Kyoto 602, Japan.

Supported in part by Grant no. 02807096 from the Ministry of Education. Science, and Culture of Japan.
We have previously noted that TOF, P-valve dysplasia, VSD, and cardiac hypertrophy occur spontaneously in WKY/NCrj rats (1). In our study, we examined the morphologic features of the cardiovascular system in fetuses and neonates. Our serial study takes advantage of this animal model.

What attracted our attention at the start of this study was the finding that the MLB of the ventricular wall was not smoothly continuous between the IVS and the LVFW and between the RVFW and the LVFW (2). In the normal heart, the MLB is smoothly continuous among these structures, constituting circumferential units that surround the left ventricle, and the left and right ventricles together $(3,4)$. The continuities were disturbed by tissue clefts, abnormal fiber arrangements, and/or myocardial fibrosis in WKY rats. The less the continuity, the greater the cardiac hypertrophy, suggesting that the discontinuities created an inability to efficiently generate pressure in the two ventricles and allow development of cardiac hypertrophy in WKY rats. Therefore, we paid particular attention to the process by which the discontinuity developed.

\section{MATERIALS AND METHODS}

We examined 159 fetuses and 110 neonates bred from eight male and 15 female WKY/NCrj rats that had been obtained in the process of selective breeding for a strain with marked cardiac hypertrophy on the basis of the electrocardiographic findings reported previously (2). Fetuses of two to eight litters each were sampled on d 17, 19, and 21 of gestation (G17, G19, G21), on the day of birth (A0), and on d 2 and 4 after birth (A2 and A4). The day after the identification of sperm in the vaginal smear was considered as the 1st $\mathrm{d}$ of gestation; birth usually occurred $22 \mathrm{~d}$ later. These WKY rats were compared with stage-matched Wistar rats of one to two litters from Shimizu Jikken Zairyo, Inc. (Kyoto, Japan).

Isolation of heart and great vessels. With the mother rats under urethane anesthesia, fetuses were removed and immersed in $10 \%$ formalin maintained at $18-20^{\circ} \mathrm{C}$ with the placenta and umbilical cord kept intact to prevent bleeding from the cord and inflation of the lung, which could affect the size of the heart and vessels. The G21 fetuses and postnatal rats, the latter being anesthetized with ether, were immersed in formalin after wide incision of the diaphragm and thorax to fix the fetal ductus arteriosus before its physiologic constriction and to prevent postmortem degeneration of organ tissues. After fixation of the whole body for several 
days, it was weighed, and the heart was removed together with the great vessels (Fig. 1).

Great vessels and foramen ovale. We measured the major (a) and minor (b) diameters of the foramen ovale at their greatest from the right side of the heart, using an eye-piece micrometer under $\times 66$ magnification to calculate the area of the foramen as $\pi \mathrm{ab} / 4$. The cross-sectional lumen area of the aorta, ductus, and PA were also determined from their major and minor diameters, the former two at the level of their junction, where their lumen size was smallest (Figs. 1 and 2).

Heart weight and ventricular wall thickness. The ventricles were cut transversely with a razor midway between the apex and the aortic root (Fig. 3) and were then weighed. We measured the greatest thickness of the IVS, the LVFW between the anterior and posterior papillary muscles, and the RVFW in the middle region without trabeculae. G17-19 fetuses were not available for the measurement of the RVFW because the internal margin of the RVFW was unclear due to the development of coarse trabeculae.

Architecture of $M L B$. The cut surface of the ventricular walls, under a dissecting microscope, showed that the MLB of the IVS
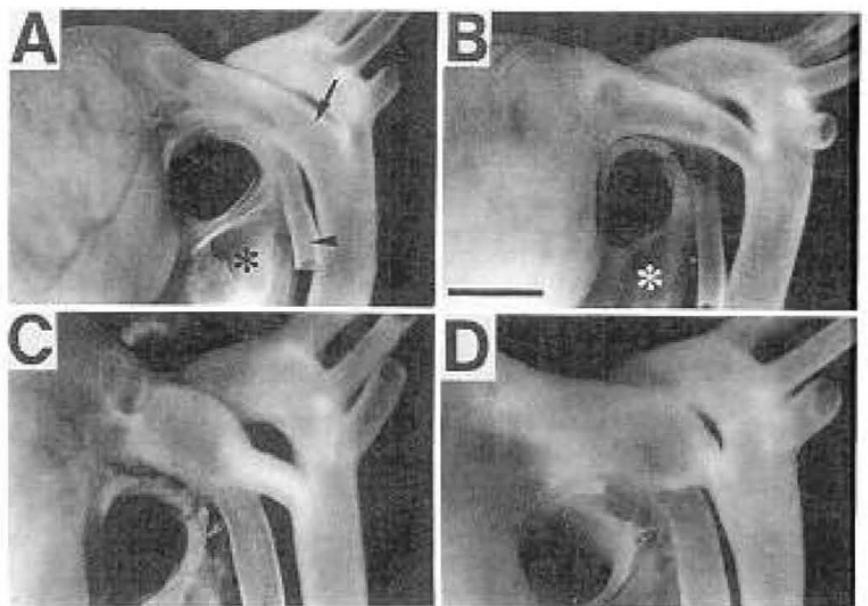

Fig. 1. Left view of the heart and great vessels. $A$, from a G19 Wistar fetus. Arrow, ductus arteriosus; arrow head, left PA. B, from a G19 WKY fetus with TOF. The ductus arteriosus is obviously smaller than the aorta at the level of their junction in $B$ and larger in A. Asterisks, left superior vena cava. $C$, from an A2 WKY neonate. The ductus is closed, producing a ligamentum arteriosum. $D$, from an $\mathrm{A} 2 \mathrm{WKY}$ neonate with TOF. The pulmonary trunk and PA are large, and the ligamentum is short. Scale bar in panel $B, 1 \mathrm{~mm}$.
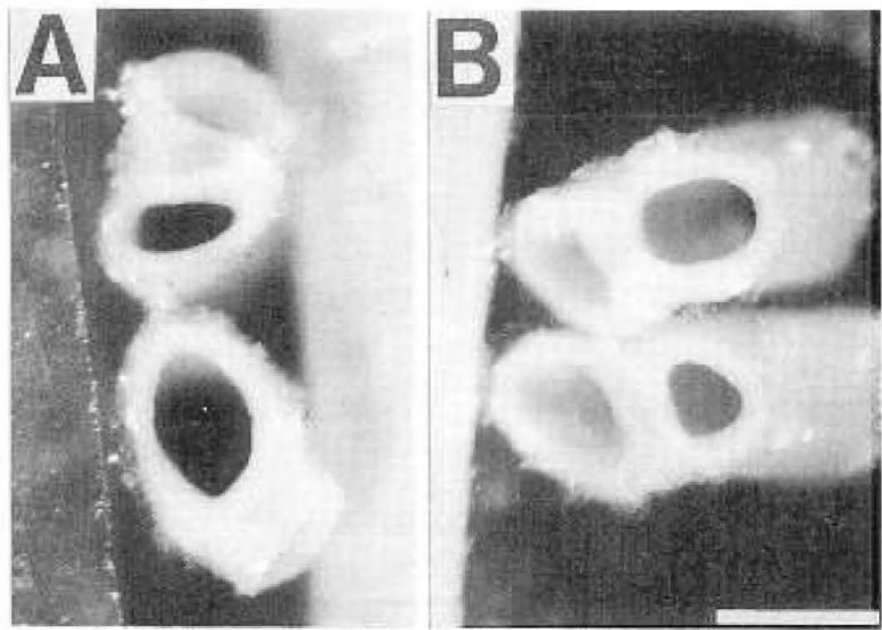

Fig. 2. Cross-section of the aorta $(A)$ and the ductus arteriosus $(B)$ just proximal to their junction. Upper, the same as in $A$ of Figure 1; lower, the same as in $B$ of Figure 1. Scale bar, $0.5 \mathrm{~mm}$. was convex toward the right and continuous with the LVFW in the Wistar rats, whereas in many of the WKY fetuses and A.0 neonates it was straight or convex toward the left and continuous with the RVFW or terminated in the subendocardium between the RVFW and the LVFW. Furthermore, many A2-4 WKY hearts showed a clear discontinuity of the septal MLB with both the LVFW and RVFW due to marked tissue clefts (Fig. 3). We assessed this abnormal situation semiquantitatively. The convexity of the septal MLB was graded from -2 (most to the left) to +2 (most to the right); the continuity of the septal MLB with the RVFW and LVFW, each in the anterior and posterior junctions, was also graded from -2 (strong continuity with the RVFW) to +2 (strong continuity with the LVFW). Thus, the total score ranged from -6 to +6 .

Valves. We examined the semilunar and atrioventricular valves in the same way as in the previous study (1) and compared them with those of Wistar rats at the same stage. We assessed qualitatively the thickness and shape of the cusps; thickening with distortion of the three cusps was considered to be severe (Fig. 4). Tissue sections of several thickened P-valves of the G21 WKY fetuses were examined histologically after being stained with hematoxylin-eosin and Masson-Goldner's trichrome.

VSD and POT. The RVFW was dissected so that VSD, POT, conal septum, and papillary muscles could be examined (Fig. 5). We determined the area of POT and VSD ostia from their major and minor diameters on the right side. The RVFW thickness was measured at the level of the POT also; this was possible in the G17-19 fetuses, because the trabeculae were dense and smoothly lined there.

PA-branch. Forty-two G21 WKY fetuses (four litters) and 42 A2 WKY neonates (four litters) were available. Specimens were dissected out from the middle $1 / 3$ between the hilus and the most distant caudal edge of the left lung, which consists of one long lobe in rats. Tissue sections were made perpendicular to the hilus-edge axis of the lobe for staining with Masson-Goldner's trichrome. Selecting the largest artery in one section, we meas-

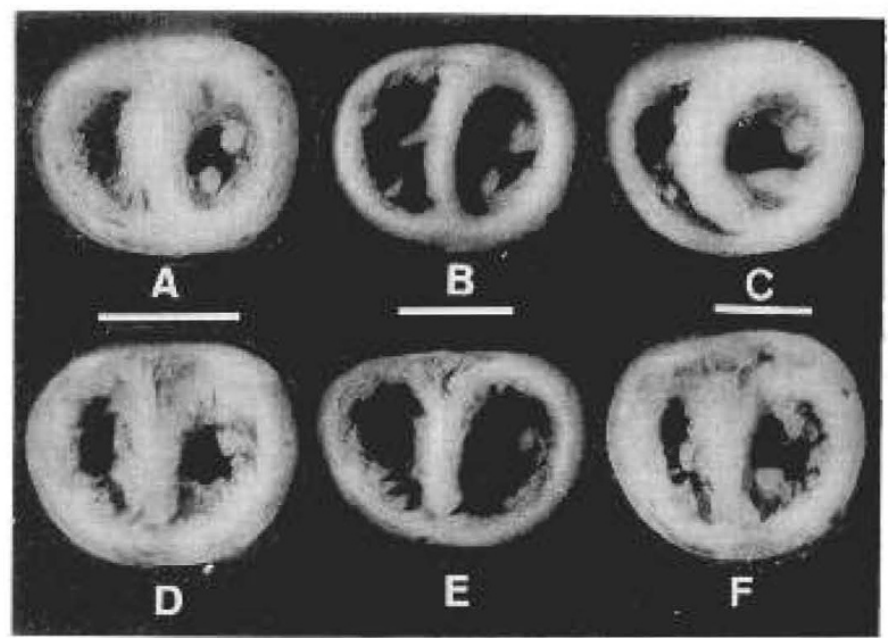

Fig. 3. Midventricular transverse view of the heart. $A, B$, and $C$, from Wistar rats at $\mathrm{G} 21, \mathrm{~A} 0$, and A4. $D, E$, and $F$, from WKY rats at the same stage as $A, B$, and $C$. The anterior surface of the heart is on the top. The heart in $D$ was accompanied by a small ductus but neither VSD nor severe P-valve dysplasia; that in $E$ and $F$, by TOF. In $A, B$, and $C$, the IVS as a whole is convex toward the right ventricular side and smoothly continuous with the LVFW. In $D$ and $E$, the IVS as a whole is not convex toward the right, and latitudinal fiber bundles of the IVS are continuous with the RVFW or terminate in the subendocardium; in $F$, the continuity of the MLB of the IVS with that of the LVFW and RVFW seems to be disturbed by tissue clefts. The grade of continuity was assessed to be 3,3 , and 5 in $A, B$, and $C$ and $-3,-3$, and 0 in $D, E$, and $F$, respectively. Left scale for $A$ and $D$, middle scale for $B$ and $E$, and right scale for $C$ and $F$ all represent $2 \mathrm{~mm}$. 

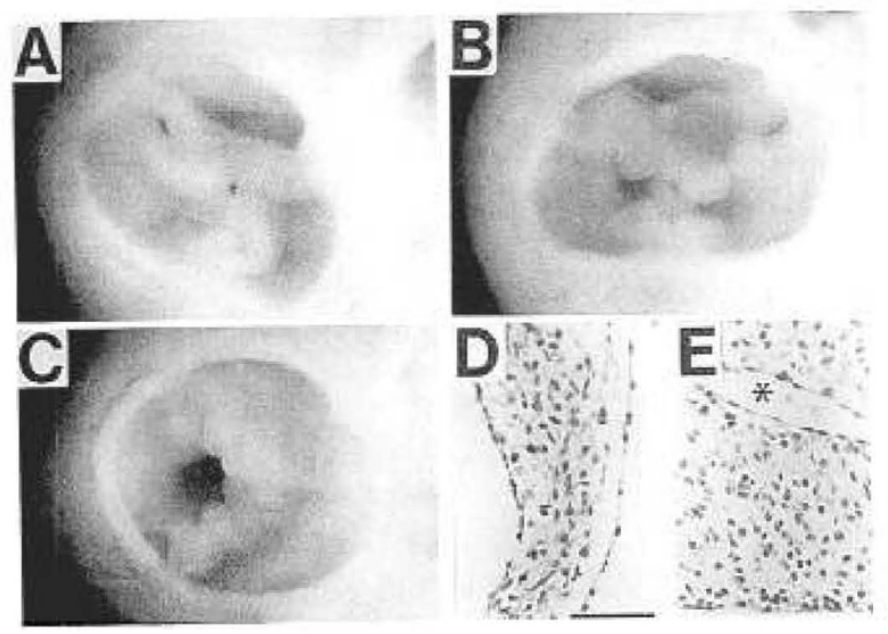

Fig. 4. $A, \mathrm{P}$-valve from a $\mathrm{G} 21 \mathrm{Wistar}$ fetus. $B$ and $C$, $\mathrm{P}$-valves from G21 WKY fetuses. The cusps are thick and distorted and their apposition seems to be impaired in both panels. They were fused and dome-shaped in $C . D$ and $E$, histology of the P-valve in $A$ and $C$. Cellular components are densely distributed with sparse collagen fibers in both panels. In $E$, there is a vessel (asterisk) with no infiltration of inflammatory cells, and the endothelium (lower edge) is obscure. Scale, $50 \mu \mathrm{m}$ for $D$ and $E$.

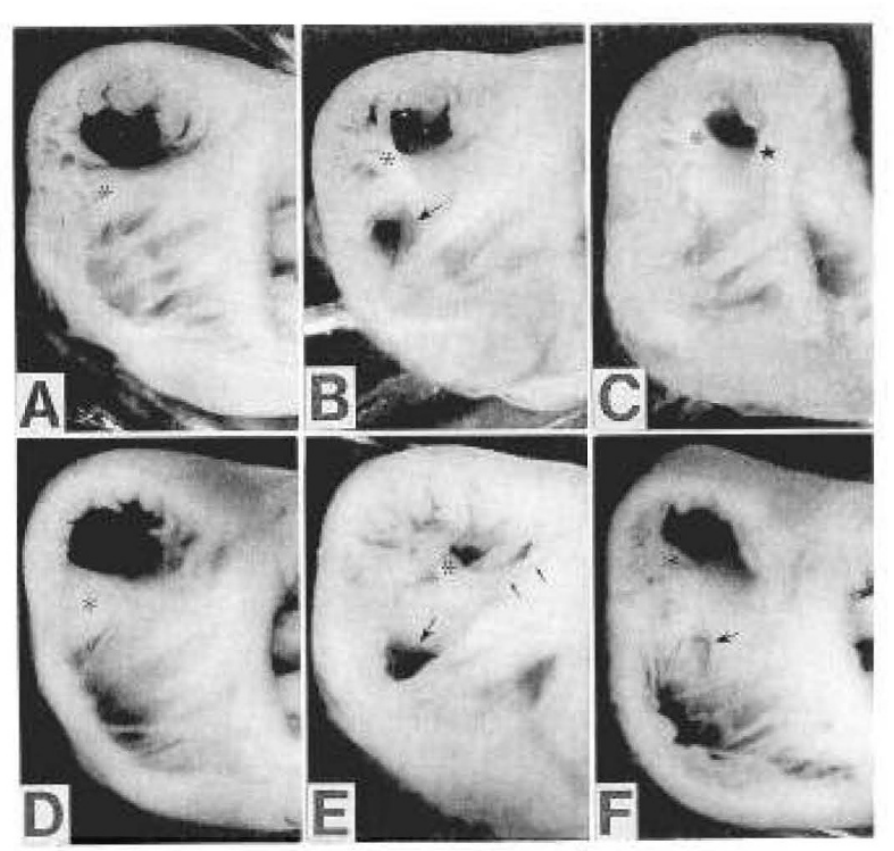

Fig. 5. $A$, the heart from a $\mathrm{G} 21$ Wistar fetus as viewed from right ventricular side with the RVFW dissected. Asterisk, crista supraventricularis. The septal band is not clear. $B$, from a G21 WKY fetus with VSD (arrow). Aortic cusps are visible through the VSD. Parietal band (asterisk) is well developed and anteriorly deviated, making the POT ostium narrow. The RVFW is not thick. $C$, from a G21 WKY fetus with no VSD but with a P-valve lesion and a small ductus arteriosus. The parietal (asterisk) and the septal (star) bands are well developed and anteriorly deviated, and the RVFW is thick, making the POT narrow. $D$, from an A2 Wistar neonate. Asterisk, crista supraventricularis. The septal band is not clear. $E$, an A2 WKY neonate with a large VSD (arrow). The RVFW is very thick. The parietal band (asterisk) is deviated anteriorly and inserted into the almost obliterated POT; the septal band (small arrows) is anteriorly deviated but does not face the POT ostium. $F$, from an A2 WKY neonate. Arrow, ventricular aneurysm. A parietal band (asterisk) is present, but the RVFW is not thick and the POT is not narrow. The edges of the tricuspid leaflets are slightly thickened. ured the major and minor lumen diameters and the thickness of the media of the arterial wall at two sites where the media was most clearly discernible to calculate the WT/LR. The WT/LR was quite similar in serial tissue sections from the same specimen. It was difficult to measure accurately the thickness of the media of smaller arteries with an eye-piece micrometer when there was no wall thickening, particularly in the fetuses.

Statistical analysis. The difference in mean values, abnormality of an individual value, percentage of abnormalities, and correlation coefficients were estimated in the same way as in the previous study (1).

\section{RESULTS}

Mortality. In the WKY rats, the mean litter size before birth $(11.4 \pm 1.3)$ was significantly greater $(p<0.05)$ than that after birth $(9.9 \pm 1.7)$, whereas there was little or no difference in the Wistar rats. This suggests that a substantial number of WKY rats die soon after birth, although dead rats could not be identified, probably because the mothers ate them. Intrauterine death was not rare in the WKY.

Valves. Severe thickening of the P-valve with distortion and impaired apposition of the three cusps, which may correspond to grade 3 thickening in adult WKY rats (1), occurred in $7-27 \%$ of the G19-A4 WKY fetuses and neonates (Table 1, Fig. 4). Obvious fusion of the cusps was very rare. The P-valve seemed to be more or less thickened with no distortion of the three cusps in many of the others. The tricuspid valve was slightly thickened at the edge and at the junctional area with chordae tendineae, usually when a severe P-valve lesion and/or a VSD was present. Severe thickening was very rare. The histology of the thickened valve in the WKY fetus did not differ essentially from that in the Wistar fetus except for increased vasculature (Fig. $4 D$ and $E)$. The aortic and mitral valves were normal.

VSD. Membranous type VSD (excluding pinhole defects) of varying size were present in 52 and $18 \%$ of the WKY fetuses at G17 and G21, respectively, and in $10-29 \%$ of the A0-A4 neonates (Table 1). In the Wistar rat, a pinhole defect was observed in the same region in two of 16 rats at G17, but never thereafter. The aortic valve was clearly visible from the right ventricle on the opposite side through the lumen when the VSD was large (Fig. $5 B$ ), indicating overriding of the aorta $(1,6)$. There were no membranous tissues in VSD before birth, but they were common after birth. A ventricular aneurysm (Fig. $5 F$ ) was present in eight of 79 A2-4 WKY rats. Severe P-valve lesions were present in about $40 \%$ of G21 and A2-4 rats with VSD (Table 2), and mild thickening existed in most of the other rats with VSD.

POT. The POT were abnormally narrow in $7-8 \%$ of the WKY rats at G17-19 and in 55-60\% at G21-A4 when compared with those of the Wistar rats at the same stages (Table 1), particularly when VSD and/or severe P-valve lesions were present in the fetuses and when VSD were present in the neonates. However, the POT were narrow in many fetuses and neonates with neither of the two lesions (Table 2). In the fetuses with narrow POT, the crista supraventicularis and well-developed parietal and septal bands were deviated anteriorly, with either a thickened or normal RVFW (Fig. $5 B$ and $C$ ). In the neonates, the parietal band sometimes inserted into the obliterated POT (Fig. $5 E$ ), or hypertrophied parietal and septal bands surrounded the ostium. Severe narrowing of the POT after birth was always accompanied by a very thick RVFW as in the adult rats; the conal RVFW was abnormally thick in $25 \%$ at G21 and $77-75 \%$ at A2-4 (Table 1). The size of the POT correlated significantly with that of the VSD at G17-19 and at A2-4, and with the conal RVFW thickness at G21 and A2-4 (Table 3).

$P A$-branch. The mean WT/LR ratio of the PA-branch decreased markedly after birth in both strains (Table 1). In some WKY fetuses and neonates, the wall media was very thick due to proliferation of smooth muscle cells (Fig. 6). The WT/LR 
Table 1. Quantitative and qualitative data of heart and arteries in Wistar and WKY rats*

\begin{tabular}{|c|c|c|c|c|c|c|}
\hline \multirow{3}{*}{$\frac{}{n \dagger}$} & \multicolumn{6}{|c|}{ Stage } \\
\hline & \multirow[t]{2}{*}{ G17 } & \multirow[t]{2}{*}{ G19 } & \multirow[t]{2}{*}{ G21 } & \multirow[t]{2}{*}{$\mathrm{A} 0$} & \multirow[t]{2}{*}{$\mathrm{A} 2$} & \multirow[t]{2}{*}{ A4 } \\
\hline & & & & & & \\
\hline Wistar & $16[1]$ & $24[2]$ & $28[2]$ & $26[2]$ & $23[2]$ & $27[2]$ \\
\hline WKY & $25[2]$ & $44[4]$ & $90[8]$ & $31[3]$ & $49[5]$ & $30[3]$ \\
\hline \multicolumn{7}{|l|}{ Body wt (g) } \\
\hline Wistar & $1.00 \pm 0.06$ & $3.15 \pm 0.17$ & $5.16 \pm 0.52$ & $6.93 \pm 0.54$ & $8.36 \pm 0.59$ & $10.70 \pm 0.90$ \\
\hline WKY & $1.20 \pm 0.12$ & $2.90 \pm 0.35$ & $4.81 \pm 0.43$ & $5.35 \pm 0.56$ & $7.08 \pm 0.97$ & $8.65 \pm 1.51$ \\
\hline P-valveł & NM & $7 \%(26 \%)$ & $17 \%(30 \%)$ & $27 \%(50 \%)$ & $13 \%(43 \%)$ & $10 \%(34 \%)$ \\
\hline $\operatorname{VSD}\left(\times 10^{3} \mu \mathrm{m}^{2}\right) \S$ & $\begin{array}{c}52 \% \\
(5-102)\end{array}$ & $\begin{array}{c}39 \% \\
(2-59)\end{array}$ & $\begin{array}{c}18 \% \| \\
(5-102)\end{array}$ & $\begin{array}{l}29 \% \\
(4-47)\end{array}$ & $\begin{array}{c}10 \% \\
(7-74)\end{array}$ & $\begin{array}{c}17 \% \\
(3-61)\end{array}$ \\
\hline \multicolumn{7}{|l|}{ POT $\left(\times 10^{3} \mu \mathrm{m}^{2}\right)$} \\
\hline Wistar & $169 \pm 22$ & $152 \pm 25$ & $144 \pm 21$ & $133 \pm 30$ & $225 \pm 399$ & $229 \pm 42$ \\
\hline WKY & $\begin{array}{c}149 \pm 23 \\
12 \%\end{array}$ & $\begin{array}{c}131 \pm 32 \\
20 \%\end{array}$ & $\begin{array}{c}93 \pm 319 \\
55 \% \|\end{array}$ & $\begin{array}{c}95 \pm 54 \\
52 \%\end{array}$ & $\begin{array}{c}132 \pm 45 \\
53 \%\end{array}$ & $\begin{array}{c}135 \pm 43 \\
60 \%\end{array}$ \\
\hline \multicolumn{7}{|c|}{ Thickness of conal RVFW $(\mu \mathrm{m})$} \\
\hline Wistar & $290 \pm 30$ & $386 \pm 36$ & $541 \pm 32$ & $510 \pm 86$ & $333 \pm 459$ & $340 \pm 42$ \\
\hline WKY & $\begin{array}{c}292 \pm 54 \\
8 \%\end{array}$ & $\begin{array}{c}377 \pm 42 \\
7 \%\end{array}$ & $\begin{array}{c}556 \pm 49 \\
25 \%\end{array}$ & $\begin{array}{c}518 \pm 95 \\
3 \%\end{array}$ & $\begin{array}{r}495 \pm 78 \\
77 \% 9\end{array}$ & $\begin{array}{c}483 \pm 94 \\
75 \%\end{array}$ \\
\hline \multicolumn{7}{|c|}{ WT/LR of PA-branch** } \\
\hline Wistar & NM & NM & $0.21 \pm 0.02$ & NM & $0.13 \pm 0.029$ & NM \\
\hline WKY & NM & NM & $\begin{array}{c}0.23 \pm 0.06 \\
19 \%\end{array}$ & NM & $\begin{array}{c}0.15 \pm 0.04 \uparrow \\
26 \%\end{array}$ & NM \\
\hline \multicolumn{7}{|l|}{ Continuity of MLB } \\
\hline Wistar & NM & $1.8 \pm 0.8$ & $1.5 \pm 0.7$ & $1.9 \pm 0.9$ & $5.1 \pm 0.69$ & $5.0 \pm 0.7$ \\
\hline WKY & NM & $\begin{array}{l}0.2 \pm 0.9 \\
<0,80 \%\end{array}$ & $\begin{array}{r}-0.8 \pm 1.4 \\
<0,81 \%\end{array}$ & $\begin{array}{r}-0.5 \pm 1.0 \\
<0,81 \%\end{array}$ & $\begin{array}{c}1.7 \pm 1.3 \pi \\
<2,75 \%\end{array}$ & $\begin{array}{r}1.5 \pm 1.2 \\
<2,80 \%\end{array}$ \\
\hline \multicolumn{7}{|c|}{ Heart wt/body wt (mg/g) } \\
\hline Wistar & $5.17 \pm 0.25$ & $4.97 \pm 0.32$ & $5.24 \pm 0.39$ & $5.32 \pm 0.43$ & $5.78 \pm 0.22 \pi$ & $5.42 \pm 0.37 \pi$ \\
\hline WKY & $\begin{array}{c}4.60 \pm 0.43 \\
0 \%\end{array}$ & $\begin{array}{c}4.61 \pm 0.54 \\
5 \%\end{array}$ & $\begin{array}{c}5.09 \pm 0.53 \\
8 \%\end{array}$ & $\begin{array}{c}5.15 \pm 1.11 \\
19 \%\end{array}$ & $\begin{array}{c}6.38 \pm 0.89 \rrbracket \\
48 \% *\end{array}$ & $\begin{array}{c}6.58 \pm 1.29 \\
53 \%\end{array}$ \\
\hline \multicolumn{7}{|l|}{ IVS/LVFW } \\
\hline Wistar & $1.68 \pm 0.10$ & $1.44 \pm 0.109$ & $1.37 \pm 0.12$ & $1.32 \pm 0.14$ & $1.07 \pm 0.099$ & $0.99 \pm 0.07$ \\
\hline WKY & $\begin{array}{c}1.60 \pm 0.16 \\
0 \%\end{array}$ & $\begin{array}{c}1.63 \pm 0.17 \\
55 \%\end{array}$ & $\begin{array}{c}1.61 \pm 0.17 \\
44 \%\end{array}$ & $\begin{array}{c}1.67 \pm 0.24 \\
68 \%\end{array}$ & $\begin{array}{c}1.27 \pm 0.18 \boldsymbol{\top} \\
53 \%\end{array}$ & $\begin{array}{c}1.20 \pm 0.21 \\
53 \%\end{array}$ \\
\hline \multicolumn{7}{|l|}{ RVFW/LVFW } \\
\hline Wistar & NM & NM & $0.90 \pm 0.10$ & $0.84 \pm 0.17$ & $0.43 \pm 0.05 \uparrow$ & $0.35 \pm 0.05 \|$ \\
\hline WKY & NM & NM & $\begin{array}{c}1.00 \pm 0.10 \\
20 \%\end{array}$ & $\begin{array}{c}1.06 \pm 0.19 \\
30 \%\end{array}$ & $\begin{array}{c}0.69 \pm 0.129 \\
87 \%\end{array}$ & $\begin{array}{c}0.65 \pm 0.20 \\
90 \%\end{array}$ \\
\hline \multicolumn{7}{|l|}{ Ductus $\left(\times 10^{3} \mu \mathrm{m}^{2}\right)$} \\
\hline Wistar & $71 \pm 8$ & $48 \pm 59$ & $41 \pm 49$ & $\mathrm{AC}$ & $\mathrm{AC}$ & $\mathrm{AC}$ \\
\hline WKY & $\begin{array}{c}60 \pm 13 \\
40 \%\end{array}$ & $\begin{array}{c}41 \pm 81 \\
38 \%\end{array}$ & $\begin{array}{c}33 \pm 79 \\
47 \%\end{array}$ & AC & $\mathrm{AC}$ & $\mathrm{AC}$ \\
\hline \multicolumn{7}{|l|}{ Aorta $\left(\times 10^{3} \mu \mathrm{m}^{2}\right)$} \\
\hline Wistar & $48 \pm 6$ & $30 \pm 4$ & $23 \pm 39$ & $29 \pm 3 \pi$ & $28 \pm 3$ & $29 \pm 2$ \\
\hline WKY & $\begin{array}{c}56 \pm 19 \\
36 \%\end{array}$ & $\begin{array}{c}38 \pm 129 \\
38 \%\end{array}$ & $\begin{array}{c}35 \pm 13 \\
51 \%\end{array}$ & $\begin{array}{r}34 \pm 16 \\
30 \% \|\end{array}$ & $\begin{array}{r}30 \pm 5 \\
15 \%\end{array}$ & $\begin{array}{r}29 \pm 5 \\
17 \%\end{array}$ \\
\hline \multicolumn{7}{|l|}{$\mathrm{PA}\left(\times 10^{3} \mu \mathrm{m}^{2}\right) \dagger \dagger$} \\
\hline Wistar & $29 \pm 4$ & $31 \pm 3$ & $30 \pm 3$ & $46 \pm 5 \pi$ & $53 \pm 4 \|$ & $56 \pm 4$ \\
\hline WKY & $25 \pm 5$ & $26 \pm 4$ & $27 \pm 3$ & $44 \pm 11 \pi$ & $58 \pm 9 \pi$ & $64 \pm 9$ \\
\hline \multicolumn{7}{|c|}{ Foramen ovale $\left(\times 10^{3} \mu \mathrm{m}^{2}\right) \dagger \dagger$} \\
\hline Wistar & $287 \pm 41$ & $150 \pm 389$ & $69 \pm 22 \pi$ & $20 \pm 19 \rrbracket$ & $\mathrm{AC}$ & $\mathrm{AC}$ \\
\hline WKY & $243 \pm 31$ & $155 \pm 279$ & $70 \pm 25$ ฯ & $33 \pm 149$ & $\mathrm{ACf}$ & ACft \\
\hline
\end{tabular}

* Values are mean \pm SD. Percentages refer to percentage of rats with an abnormal finding. All area values were corrected by body wt (g) raised to the power of $2 / 3$. Abbreviations: NM, not measured or not clear; AC, almost completely closed.

$\dagger$ Square brackets, number of litters.

$\$$ Percentage of WKY rats with severe thickening (mild thickening in parentheses).

$\S$ Percentage of WKY rats with VSD and range of size in parentheses.

$\| P<0.05$; significantly different from the value in the preceding stage.

I $P<0.01$; significantly different from the value in the preceding stage.

** Number of G21 and A2 WKY rats tested for WT/LR ratio of PA-branch was 42 (four litters).

t† Number of G21 WKY rats tested for the PA and for the foramen ovale was 44 (four litters).

ft Patent in four of the A2-4 neonates. 
Table 2. Relations between various abnormalities*

\begin{tabular}{|c|c|c|c|c|c|}
\hline & $\begin{array}{c}\text { No abnormality } \\
\text { of MLB or P-valve, } \\
\text { no VSD }\end{array}$ & $\begin{array}{c}\text { Disordered MLB } \\
\text { without P-valve } \\
\text { lesion or VSD }\end{array}$ & $\begin{array}{l}\text { P-valve lesion } \\
\text { without VSD }\end{array}$ & & VSD \\
\hline \multicolumn{6}{|l|}{$n \dagger$} \\
\hline G21 [90] & [16] & {$[50]$} & {$[8]$} & {$[16]$} & $7 \ddagger$ \\
\hline $\mathrm{A} 2-4[79]$ & [17] & {$[48]$} & [4] & {$[10]$} & $5 \ddagger$ \\
\hline \multicolumn{6}{|l|}{ POT } \\
\hline G21 [50] & (2) $121 \pm 24$ & (25) $97 \pm 25 \S$ & (8) $76 \pm 16 \S \|$ & $(15)$ & $63 \pm 31 \S$ \\
\hline A2-4 [44] & (5) $159 \pm 33$ & (30) $131 \pm 38$ & (1) $160 \pm 56$ & $(8)$ & $104 \pm 63 \S \|$ \\
\hline \multicolumn{6}{|c|}{ Heart wt/body wt } \\
\hline G21 [7] & (0) $4.89 \pm 0.33$ & (0) $4.90 \pm 0.39$ & (2) $5.64 \pm 0.62 \S \|$ & $(5) 5$ & $5.54 \pm 0.60 \S$ \\
\hline A2-4 [39] & (3) $5.96 \pm 0.37$ & (23) $6.20 \pm 0.57$ & (3) $6.84 \pm 0.35 \S$ & $(10) \&$ & $8.51 \pm 1.34 \S \|$ \\
\hline \multicolumn{6}{|l|}{ IVS/LVFW } \\
\hline G21 [40] & (4) $1.57 \pm 0.13$ & (22) $1.60 \pm 0.16$ & (6) $1.71 \pm 0.17 \S$ & (8) & $1.61 \pm 0.20$ \\
\hline $\mathrm{A} 2-4[42]$ & (7) $1.19 \pm 0.14$ & (24) $1.24 \pm 0.18$ & (2) $1.26 \pm 0.06$ & (9) & $1.50 \pm 0.30 \S \|$ \\
\hline \multicolumn{6}{|c|}{ RVFW/LVFW } \\
\hline G21 [18] & (3) $0.98 \pm 0.08$ & (7) $1.01 \pm 0.10$ & (6) $1.15 \pm 0.08 \S \|$ & (2) $\mathrm{C}$ & $0.95 \pm 0.16 \|$ \\
\hline A2-4 [70] & (11) $0.57 \pm 0.10$ & (45) $0.66 \pm 0.11 \S$ & (4) $0.68 \pm 0.10 \S$ & (10) $c$ & $0.92 \pm 0.21 \S \|$ \\
\hline \multicolumn{6}{|l|}{ Ductus } \\
\hline G21 [42] & (2) $39 \pm 4$ & (21) $34 \pm 4 \S$ & (6) $26 \pm 7 \S \|$ & (13) & $26 \pm 9 \S$ \\
\hline \multicolumn{6}{|l|}{ Aorta } \\
\hline G21 [46] & (3) $27 \pm 8$ & (22) $31 \pm 6$ & (7) $40 \pm 6 \S \|$ & (14) & $54 \pm 17 \S \|$ \\
\hline A2-4 [12] & (1) $28 \pm 3$ & (2) $28 \pm 3$ & (1) $32 \pm 1$ & $(8)$ & $39 \pm 5 \S \|$ \\
\hline
\end{tabular}

* Values are mean \pm SD concerning the left item when rats have the abnormality on the top. Parentheses, number of rats with both the abnormality of the left item and that on the top. The total number in parentheses in a line equals the number in the left square bracket.

$\dagger$ Square brackets, number of rats with abnormalities.

$\ddagger$ Number of rats that have P-valve lesion also.

$\S p<0.05$, for comparison with the mean value in first column.

$\| p<0.05$, for comparison with the value in just the left column.

Table 3. Relations between quantitative data*

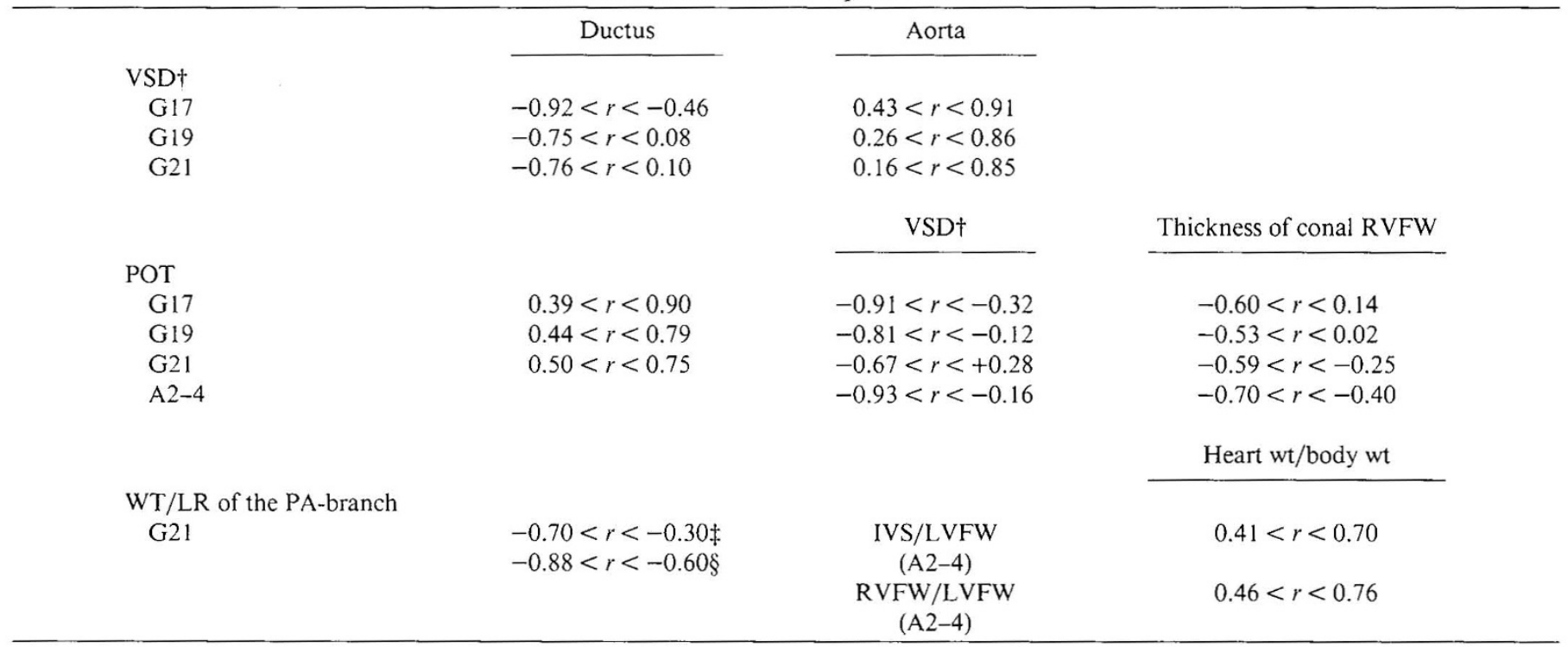

$* r$, correlation coefficients between items on the line and on the top expressed as a $95 \%$ confidence interval.

+ Rats with no VSD are not included.

$\ddagger$ Rats with VSD are included.

$\S$ Rats with VSD are not included.

ratio was abnormally high in eight of the 42 G21 WKY fetuses, in some of which there were severe P-valve lesions and/or slightly narrow POT, but no VSD. After birth, the WT/LR was high in 11 of the 42 A2 neonates; five of them had VSD. In the other six, there were no VSD, severe P-valve lesions, or POT stenosis. In one neonate with a large VSD and an obliterated POT (Fig. $5 E)$, the WT/LR ratio was not high.

Architecture of MLB. In both the Wistar and the WKY rats, the degree of continuity of the MLB increased markedly at A2-
4. However, in $80 \%$ of the WKY rats, the degree of continuity was abnormally low compared with that in the Wistar rats at all the stages examined (Table 1).

Cardiac hypertrophy. The heart wt/body wt was abnormally high in only $5-8 \%$ of the G19-21 WKY fetuses and in about $50 \%$ of the A2-4 neonates. In both strains, the IVS/LVFW and RVFW/LVFW ratios were very high before birth and decreased markedly after birth, with many of the WKY rats showing abnormally high ratios after birth (Table 1). In the A2-4 WKY 


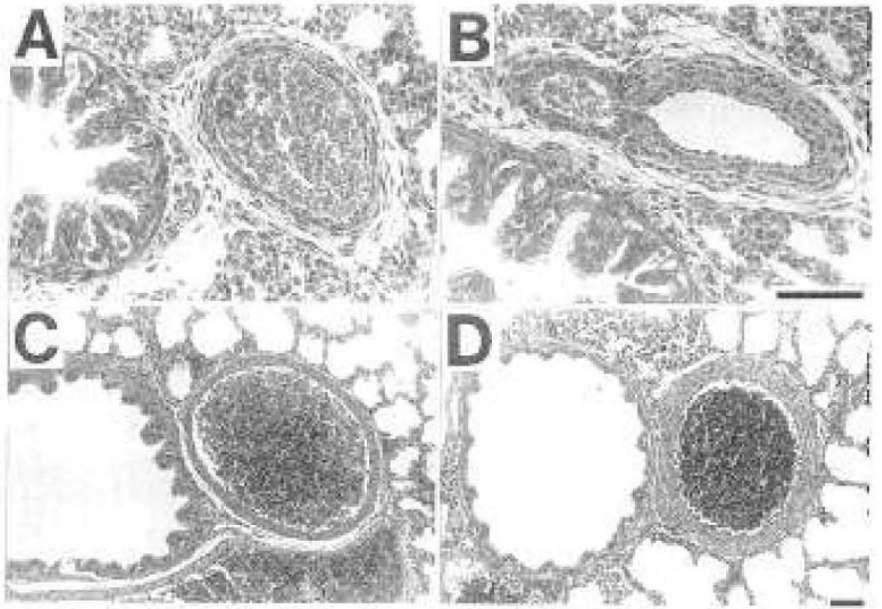

Fig. 6. Bronchiole and artery in the lung. $A$, from a G21 Wistar fetus. $B$, from a G21 WKY fetus with a small ductus arteriosus but with no VSD. $C$, from an A2 Wistar rat. $D$, from an A2 WKY rat with TOF. In $B$ and $D$, the arterial wall is markedly thickened due to proliferation of smooth muscle cells of the media. The wall of a smaller branch is also thick in $B$. Upper scale is for $A$ and $B$, lower scale for $C$ and $D$; both, 50 $\mu \mathrm{m}$.

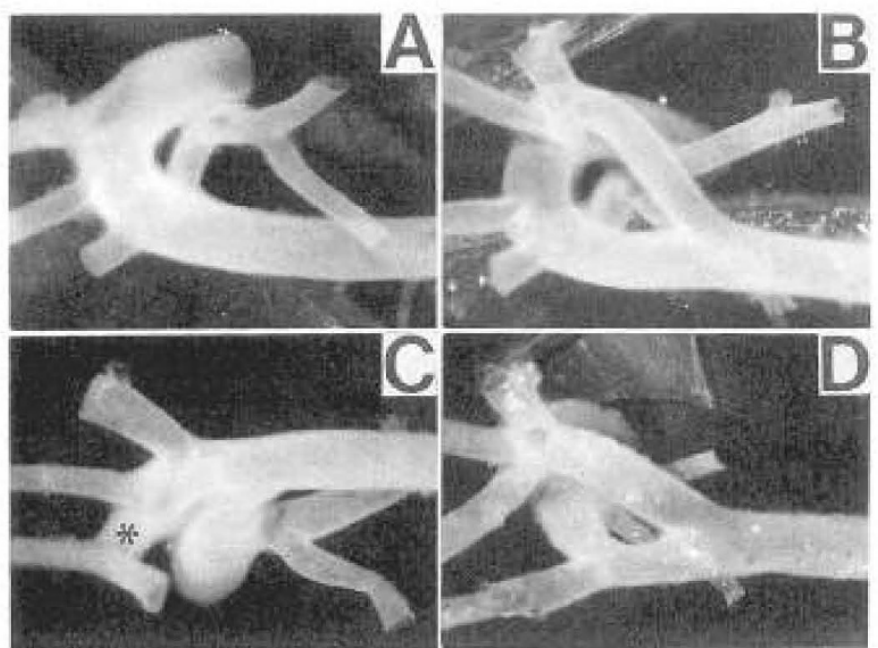

Fig. 7. Dorsal view of great vessels of WKY rats with right side of rats on the top. $A$, left aortic arch from a $\mathrm{G} 21$ fetus. $B$, double aortic arch from a G21 fetus. The right common carotid and subclavian arteries diverge directly from the right aortic arch with no brachiocephalic artery. $C$, right aortic arch with a right ductus arteriosus from an $\mathrm{A} 0$ neonate. The left brachiocephalic artery (asterisk) gives off the left common carotid and left subclavian arteries. $D$, right aortic arch with a left ductus from a G21 fetus. The aortic arch first gives off the left common carotid artery, and then the right common carotid and right subclavian arteries. The left subclavian artery diverges from the portion distal to the ductus. Arterial branching from the aortic arch in other rats with aortic arch anomalies showed the same pattern as in these rats according to the type of anomalies. The vascular ring in $B$ and $D$ was penetrated by the trachea and esophagus. In $A$ and $C$, a single PA diverges from the pulmonary trunk, which then gives off right and left branches. The ductus is very small in $A$ and $B$ and moderate in $D$. All the hearts had TOF and were in situs solitus.

rats, the heart wt/body wt correlated significantly with the IVS/ LVFW and the RVFW/LVFW (Table 3). There was also a good correlation between the IVS/LVFW and RVFW/LVFW ratios $(0.52<r<0.77)$.

These three ratios were high after birth, especially when VSD and/or severe P-valve lesions were present (Table 2). However, neither of these lesions was present in 26 of the 39 A2-4 rats with heavy hearts, and in 31 of the 42 rats with disproportionate septal thickening (Table 2). Instead, there was a decrease in continuity of the MLB between the IVS and LVFW in most of the rats without the two lesions. Ventricular aneurysms were present in four of the 26 rats with heavy hearts but no severe Pvalve lesions. In 19 neonates with heavy hearts, in which the PAbranch was also examined, there were VSD and/or P-valve lesions in nine rats and isolated PA-branch lesions in two rats; all the remaining rats showing a decreased continuity of the MLB.

Great vessels and foramen ovale. The ductus arteriosus was abnormally small in $38-47 \%$ of the WKY fetuses, whereas the aortic isthmus was abnormally large in $36-51 \%$ of them (Figs. 1 and 2, Table 1). The PA tended to be smaller before birth but larger after birth in the WKY than in the Wistar rats. The PA and pulmonary trunk were markedly enlarged in the WKY neonates with VSD and/or severe P-valve lesions (Fig. $1 D$ ). The size of the foramen ovale varied greatly, and the mean value was similar in the two strains at every stage. In four of the A2-4 WKY neonates with VSD, the foramen was patent.

A double aortic arch was present in four, and a right aortic arch with a left or right ductus in six of the WKY fetuses and neonates, many of which had a small ductus, a VSD, a P-valve lesion, and/or TOF (Fig. 7). In 132 of the 269 WKY rats, a single PA diverged directly from the pulmonary trunk, which then separated into the right and left arteries. In the Wistar rats, the left and right PA always branched separately from the pulmonary trunk. The left superior vena cava was always present in both the Wistar and WKY rats (Fig. $1 A$ and $B$ ).

The fetal ductus was usually small but the aortic isthmus was large when there were VSD, P-valve lesions, marked rightward continuity of the septal MLB (Table 2), marked POT narrowing, and/or PA-branch lesions. There were significant correlations between the size of VSD and that of the ductus and the aorta, especially at G17; moreover, the size of the ductus correlated significantly with that of POT, and with the WT/LR ratio of the PA-branch (Table 3).

\section{DISCUSSION}

This study demonstrates the coexistence of various cardiovascular abnormalities that occur during inbreeding of WKY rats. Because of the high frequency of congenital heart disease, we were able to follow serially the cardiac anomalies in these animals. These observations suggest several possible causal mechanisms, in addition to the obvious genetic one, in the development of the anomalies from fetal to postnatal life. In particular, our data support the concept of Van Mierop et al. (11) that hemodynamic changes caused by one defect induce a constellation of abnormalities during late fetal life.

Thickening and distortion of the P-valves, usually accompanied by mild lesions of the tricuspid valve, was present before birth in WKY rats and the incidence was similar to that in neonates and adults (1), suggesting a congenital or developmental origin with persistence after birth. The increased vasculature in the cusps of dysplastic P-valves (1) was also present before birth, which may reflect an increased requirement of blood to supply the greater tissue mass, as has been suggested in dogs (5).

The incidence of VSD in the fetuses decreased as the stage advanced, which suggests that the normal process of muscular closure of the IVS region is delayed but is still in progress until birth. Membranous tissues in VSD appeared immediately after birth, with some of them possibly closing VSD. This, together with neonatal death, may explain the lower incidence of VSD in the A2-4 neonates and adults (1) than in G21 fetuses.

POT narrowing before birth seems related to anterior deviation of the crista supraventricularis and development of anteriorly deviated parietal and septal bands, which occurred in the absence of VSD also, and partly to thickening of the outflow RVFW. Constriction of the POT may progress after birth due to further 
thickening of the outflow RVFW, especially when VSD are present. The way in which the parietal and septal bands participate in the POT narrowing after birth is variable (6).

The association of TOF with a double or right aortic arch (6), agenesis of the ductus arteriosus, and a large aorta $(7,8)$ is not rare in humans. Anomalies of the great vessels attributable to abnormal development of the aortic arch system that derives from the neural crest (9) have been described in Keeshond dogs also $(10,11)$.

What relationships are there among these abnormalities in rats? P-valve lesions, together with VSD and absence of the papillary muscle of the conus (1), may be the result of the primarily occurring hypoplasia or dysplasia of the conotruncal septum, as has already been suggested in the study on Keeshond dogs $(10,11)$. Underdevelopment of the pulmonary infundibulum may be the basic malformation as suggested in humans (8).

If so, under an elevated right ventricular pressure due to stenosis of the P-valve or POT, the VSD may allow a substantial amount of right-to-left shunting, possibly together with a flow increase through the foramen ovale, leading to enlargement of the aorta and hypoplasia of the ductus in accord with changes of their flow volume-a mechanism that has also been proposed in the study of humans (8) and dogs (10). This possibility is supported by our findings that the size of the aorta correlated with the size of the VSD. Moreover, the size of the ductus showed negative correlation with that of VSD, but was positively correlated with the size of POT, particularly in G17 WKY fetuses.

However, it has been stated that the occasional occurrence of aortic arch defects in dogs with no obvious defects of the heart suggests that the above interpretation may not be correct (10). This applies to WKY rats also. Rather, agenesis or premature closure of a ductus may lead to fetal cardiac failure and death in the absence of large intracardiac communications (7); this may in part be supported by human autopsy studies (12) and experimental studies in dogs (13). Thus, if the ductus arteriosus is primarily hypoplastic in many of the WKY fetuses, a VSD should be favorable as a vent for the right ventricle.

The wall thickening of the PA-branches associated with VSD after birth is likely secondary to the hemodynamic effects of the VSD (14). The PA-branch lesions in the WKY neonates in the absence of VSD, which are considered to be continuous with those before birth, may be comparable to persistent pulmonary hypertension of the newborn in humans (14).

It has been demonstrated that a significant elevation of pressure in the pulmonary trunk results from constriction of the ductus arteriosus induced pharmacologically (15-17) or surgically (18). Studies on lambs (17-20) and humans $(21,22)$ have indicated that wall thickening of the PA-branches results from chronic constriction of the ductus and leads to the development of sustained pulmonary hypertension after birth. A small ductus in the WKY fetuses may have exerted a similar effect on the PAbranch. In this case, the patency of the IVS region may prevent the wall thickening by reducing the pressure overload on the right ventricle.

The MLB of the IVS was continuous with the RVFW in many of the WKY fetuses. This situation in the fetus may be inadequate for the generation of pressure in the left ventricle, particularly after birth when the afterload on the left ventricle increases rapidly. This abnormal situation, if it is not readily resolved after birth, may predispose to discontinuity of the MLB between the IVS and LVFW, and between the RVFW and the LVFW. This may in turn participate in the postnatal development of cardiac hypertrophy with myocardial lesions similar to those of hypertrophic cardiomyopathy (2) in association with, or independently of, the hemodynamic effects of the P-valve lesions, VSD, narrow POT, and PA-branch lesions.

The abnormality of the septal MLB could be a primary lesion or could occur secondarily. The continuity of the MLB between the IVS and RVFW is favorable for the generation of pressure in the right ventricle. This idea tempts us to suggest that the abnormality may be secondary to a pressure overload on the right ventricle, which may be imposed by P-valve lesions, PAbranch lesions, narrow POT, and/or small ducti. It has been suggested that the myofibrils in the embryonic heart are aligned in accord with the direction of the mechanical stress imposed on them $(23,24)$.

In lambs, a degenerative change of the tricuspid valve was associated with pharmacologic constriction of the ductus, which has been suggested to result from the direct effect of the pressure elevation in the right ventricle (19). The elevated pressure may augment the mechanical stimulus to closure of the valve which is still developing and is susceptible to the stimulus. If this idea were applied to the tricuspid and P-valves in WKY rats, it could explain the selective involvement of cardiac valves on the right side.

In the fetuses of both rat strains, the IVS/LVFW and RVFW/ LVFW ratios were very high-as has already been noted in normal humans (25) and rats (26). Unlike the hearts of neonates, the fetal hearts of the WKY tended to be only slightly heavy even when VSD, POT narrowing, P-valve, and/or PA-branch lesions were present. The lesions may have progressed after birth to such a degree that they led to the rapid increase in heart weight. However, progression of POT narrowing and new involvement of the PA-branch were seen after birth in only a relatively few rats with VSD. The functional significance of these lesions may be quite different between the fetus and the neonate because of their underlying hemodynamics; e.g. POT, P-valve, and PA-branch lesions will impose a much higher afterload on the right ventricle after birth than before birth when the foramen ovale and ductus are patent (27). Moreover, it is unlikely that an isolated VSD in the fetus causes a large shunt, because the pressures in the two ventricles are normally equal in the fetal circulation (27).

There are many possible interpretations of the interrelations between various cardiovascular abnormalities of WKY fetuses and neonates. The pathogenesis and implication of these abnormalities and their associations in the rat remain to be elucidated by further detailed studies, which will be facilitated by the wide availability of this genetically abnormal strain of rats with congenital heart disease.

Acknowledgments. The authors thank Dr. Alice Cary, Kyoto Baptist Hospital and Dr. Masahiko Ando, Tokyo Woman's Medical College, for reviewing the manuscript, and Mr. Masayoshi Kitagawa, Takeda Chemical Industries, Ltd., for raising the rats.

\section{REFERENCES}

1. Kuribayashi T, Shimoo K, Nakamura T, Taniwaki H, Kenji Hamaoka K, Nakagawa M, Ibata Y, Komeda T, Nagaoka A 1990 Tetralogy of Fallot, pulmonary valve stenosis, ventricular septal defect, and hypertrophic cardiomyopathy in WKY/NCri rats. Pediatr Res 27:483-487

2. Kuribayashi T, Mizuta T, Shimoo K, Kubota Y, Katsume H, Nakagawa M, Ibata Y 1988 Spontaneously occurring hypertrophic cardiomyopathy in the rat. II. Distribution of, and correlations between, various cardiac abnormalities in the WKY/NCrj and its related strains. Jpn Circ J 52:1156-1170

3. Robb JS, Robb RC 1942 The normal heart. Anatomy and physiology of the structural unit. Am Heart J 23:455-467

4. Kuribayashi T, Furukawa K, Katsume H, ljichi H, Ibata Y 1986 Regional differences of myocyte hypertrophy and three-dimensional deformation of the heart. Am J Physiol 250:H378-H388

5. Patterson DF, Haskins ME, Schnarr WR 1981 Hereditary dysplasia of the pulmonary valve in beagle dogs. Am J Cardiol 47:631-641

6. Guntheroth WG, Kawabori I, Baum D 1983 Tetralogy of Fallot. In: Adams FH, Emmanouilides GC (eds) Heart Disease in Infants, Children, and Adolescents, 3rd Ed. Williams \& Wilkins, Baltimore, pp 215-227

7. Emmanouilides GC, Thanopoulos B, Siassi B, Fishbein M 1976 "Agenesis" of ductus arteriosus associated with the syndrome of tetralogy of Fallot and absent pulmonary valve. Am J Cardiol 37:403-409

8. Van Praagh R, Van Praagh S, Nebesar RA, Muster AJ, Sinha SN, Paul MH 1970 Tetralogy of Fallot: underdevelopment of the pulmonary infundibulum and its sequelae. Am J Cardiol 26:25-33

9. Morriss-Kay G, Tan S-S 1987 Mapping cranial neural crest cell migration pathway in mammalian embryos. Trends Genet 3:257-261 
10. Patterson DF, Pyle RL, Mierop L, Melbin J, Olson M 1974 Hereditary defects of the conotruncal septum in Keeshond dogs: pathologic and genetic studies. Am J Cardiol 34:187-205

11. Van Mierop LHS, Patterson DF, Schnarr WR 1977 Hereditary conotruncal septal defects in Keeshond dogs: embryologic studies. Am J Cardiol 40:936950

12. Becker AE, Becker MJ, Wagenvoort 1977 Premature contraction of the ductus arteriosus: a cause of foetal death. J Pathol 121:187-191

13. Haller Jr JA, Morgan WW, Rodgers BM, Gengos DG, Margulies SI 1967 Chronic hemodynamic effects of occluding the fetal ductus arteriosus. Pathologic and cineangiographic studies in fetal dogs. J Thorac Cardiovasc Surg 54:770-776

14. Rabinovitch M 1983 Pulmonary hypertension. In: Adams FH, Emmanouilides GC (eds) Heart Disease in Infants, Children, and Adolescents, 3rd Ed. Williams \& Wilkins, Baltimore, pp 669-692

15. Heymann MA, Rudolph AM 1976 Effects of acetylsalicylic acid on the ductus arteriosus and circulation in the fetal lambs in utero. Circ Res 38:418-422

16. Hoskins EJ, Kirkpatrick SE, Friedman WF 1979 Pulmonary aortic pressure gradients as index of caliber of fetal patent ductus arteriosus. Am J Obstet Gynecol 135:543-545

17. Friedmann WF, Printz MP, Kirkpatrick SE, Hoskins EJ 1983 The vasoactivity of the fetal lamb ductus arteriosus studied in utero. Pediatr Res 17:331-337

18. Levin DL, Hyman AI, Heymann MA, Rudolph AM 1978 Fetal hypertension and the development of increased pulmonary vascular smooth muscle: a possible mechanism for persistent pulmonary hypertension of the newborn infant. J Pediatr 92:265-269

19. Levin DL, Mills LJ, Weinberg AG 1979 Hemodynamic, pulmonary vascular, and myocardial abnormalities secondary to pharmacologic constriction of the fetal ductus arteriosus. A possible mechanism for persistent pulmonary hypertension and transient tricuspid insufficiency in the newborn infant. Circulation 60:360-364

20. Wild AM, Nickerson PA, Morin III FC 1989 Ligating the ductus arteriosus before birth remodels the pulmonary vasculature of the lamb. Pediatr Res 25:251-257

21. Levin DL, Fixler DE, Morriss FC, Tyson J 1978 Morphologic analysis of the pulmonary vascular bed in infants exposed in utero to prostaglandin synthetase inhibitors. J Pediatr 92:478-483

22. Manchester D, Margolis HS, Sheldon RE 1976 Possible association between maternal indomethacin therapy and primary pulmonary hypertension of the newborn. Am J Obstet Gynecol 126:467-469

23. Manasek FJ 1970 Histogenesis of the embryonic myocardium. Am J Cardiol 25:149-168

24. Isobe Y, Shimada Y 1983 Myofibrillogenesis in vitro as seen with the scanning electron microscope. Cell Tissue Res 231:481-494

25. Maron BJ, Verter J, Kapur S 1978 Disproportionate ventricular septal thickening in the developing normal human heart. Circulation 57:520-526

26. Momma K, Takao A, Ito R, Nishikawa T 1987 In situ morphology of the heart and great vessels in fetal and newborn rats. Pediatr Res 22:573-580

27. Heymann MA, Rudolph AM 1972 Effects of congenital heart disease on fetal and neonatal circulations. Prog Cardiovasc Dis 15:115-143 